\title{
Sistem Pengambilan Keputusan Penentuan Lokasi Tempat Pembuangan Akhir (Tpa) Sampah Menggunakan Metode Simple Addictive Weighting (Saw)
}

\author{
Yani Sugiyani \\ Program Studi Sistem Informasi Fakultas Teknologi Informasi Universitas Serang Raya \\ J. Raya Cilegon Serang Drangong Taktakan Kota Serang Banten Indonesia \\ yani.sugiyani@gmail.com
}

\begin{abstract}
Sampah adalah suatu bahan yang terbuang atau dibuang dari sumber hasil aktifitas manusia maupun alam yang belum memiliki nilai ekonomis. Sampah berasal dari rumah tangga, pertanian, perkantoran, perusahaan, rumah sakit, pasar, dan lain-lain. Permasalahan sampah menjadi keluhan seluruh masyarakat desa maupun kota, oleh karena itu perlu ditangani agar tidak menimbulkan masalah yang berkelanjutan. Terdapat beberapa permasalahan yang sudah timbul terkait dengan operasional Tempat Pembuangan Akhir (TPA) yaitu pertumbuhan penyakit, pencemaran udara, asap pembakaran, gangguan kebisingan dan dampak sosial terhadap warga sekitar lokasi TPA. Banyak cara mengatasi permasalahan sampah tersebut salah satunya dengan mengadakan lokasi TPA sampah. TPA merupakan tempat dimana sampah mencapai tahapterakhir dalam pengelolaannya sejak mulai timbul di sumber, pengumpulan, pemindahan/pengangkutan, pengolahan dan pembuangan. TPA merupakan tempat dimana sampah diisolasi secara aman agar tidak menimbulkan gangguan terhadap lingkungan sekitarnya. Kabupaten Pandeglang merupakan salah satu kabupaten yang berada di wilayah Provinsi Banten. Dalam setiap unit kerja yang ada pada Dinas Kabupaten Pandeglang, terdapat salah satu Dinas yang bertugas mengelola kebersihan yaitu Dinas Cipta Karya, Penataan Ruang dan Kebersihan. . Oleh karena itu, pemerintah Kabupaten Pandeglang khususnya Dinas Cipta Karya Kabupaten Pandeglang dengan adanya sistem pendukung keputusan akan sangat membantu Dinas Cipta Karya dalam menentukan lokasi TPA sampah. Dengan SPK ini pemerintah Kabupaten Pandeglang akan lebih mudah dalam menentukan lokasi TPA. Metode yang di pakai dalam sistem ini adalah metode Simple Addictive Weighting (SAW) yang merupakan suatu model pendukung keputusan yang seringjuga dikenal istilah metode penjumlahan terbobot dari rating kerja pada setiap alternatif pada semua atribut. Metode SAW ini cukup efektif dalam menyederhanakan dan mempercepat proses serta hasil pengambilan keputusan yang merupakan metode yang cukup fleksibel dan dapat membuat keputusan yang terbaik dan tepat untuk menentukan lokasi TPA sampah rekomendasi di Kabupaten Pandeglang.
\end{abstract}

Kata Kunci : sampah, TPA, lokasi, Simple Addictive Weighting (SAW), pengambilan keputusan

\section{PENDAHULUAN}

Sampah adalah suatu bahan yang terbuang atau dibuang dari sumber hasil aktifitas manusia maupun alam yang belum memiliki nilai ekonomis. Sampah berasal dari rumah tangga, pertanian, perkantoran, perusahaan, rumah sakit, pasar, dan lain-lain. Permasalahan sampah menjadi keluhan seluruh masyarakat desa maupun kota, oleh karena itu perlu ditangani agar tidak menimbulkan masalah yang berkelanjutan.

Terdapat beberapa permasalahan yang sudah timbul terkait dengan operasional Tempat Pembuangan Akhir (TPA) yaitu pertumbuhan penyakit, pencemaran udara, asap pembakaran, gangguan kebisingan dan dampak sosial terhadap warga sekitar lokasi TPA.

Banyak cara mengatasi permasalahan sampah tersebut salah satunya dengan mengadakan lokasi TPA sampah. TPA merupakan tempat dimana sampah mencapai tahapterakhir dalam pengelolaannya sejak mulai timbul di sumber, pengumpulan, pemindahan/pengangkutan, pengolahan dan pembuangan. TPA merupakan tempatdimana sampah diisolasi secara aman agar tidak menimbulkan gangguan terhadap lingkungan sekitarnya

Kabupaten Pandeglang merupakan salah satu kabupaten yang berada di wilayah Provinsi Banten. Dalam setiap unit kerja yang ada pada Dinas Kabupaten Pandeglang, terdapat salah satu Dinas yang bertugas mengelola kebersihan yaitu Dinas Cipta Karya, Penataan Ruang dan Kebersihan.

Dinas Cipta Karya, Penataaan Ruang dan Kebersihan Kabupaten Pandeglang merupakan Dinas yang bertugas mengelola air bersih, penyehatan lingkungan, pembangunan gedung, pemetaan dan pemanfaatan ruang termasuk TPA, kebersihan, pertamanan, dan pengolaan limbah.

Dalam Program kerja Dinas Cipta Karya dalam menentukan lokasi TPA membutuhkan sebuah sarana yang dapat membantu Dinas Cipta Karya dalam menentukan lokasi TPA yang tepat. Sarana yang dapat digunakan adalah dengan membuat sebuah sistem pendukung keputusan penentuan 
lokasi TPA. SPK yang akan digunakan adalah dengan menentukan lokasi TPA berdasarkan kriteria yang telah ditentukan yaitu luas lahan, jumlah penduduk, curah hujan dan jumlah timbulan sampah.

Bersumber dari Draft Buku Putih Sanitasi Kabupaten Pandeglang (2010), secara administratif Kabupaten Pandeglang terdiri dari 35 kecamatan dengan luas keseluruhan 2.746,89 $\mathrm{km}^{2}$ dan saat ini memiliki 2 (dua) TPA sampah yaitu TPA Bangkonol di Kecamatan Keroncong dan TPA Bojong Canar di Kecamatan Cikeudal, sehingga kuantitas (jumlah) TPA di Kabupaten Pandeglang masih kurang untuk menjangkau wilayah pelayanan jaringan persampahan.

Oleh karena itu, pemerintah Kabupaten Pandeglang khususnya Dinas Cipta Karya Kabupaten Pandeglang dengan adanya sistem pendukung keputusan akan sangat membantu Dinas Cipta Karya dalam menentukan lokasi TPA sampah. Dengan SPK ini pemerintah Kabupaten Pandeglang akan lebih mudah dalam menentukan lokasi TPA.

Metode yang di pakai dalam sistem ini adalah metode Simple Addictive Weighting (SAW) yang merupakan suatu model pendukung keputusan yang seringjuga dikenal istilah metode penjumlahan terbobot dari rating kerja pada setiap alternatif pada semua atribut. Metode SAW ini cukup efektif dalam menyederhanakan dan mempercepat proses serta hasil pengambilan keputusan yang merupakan metode yang cukup fleksibel dan dapat membuat keputusan yang terbaik dan tepat untuk menentukan lokasi TPA sampah rekomendasi di Kabupaten Pandeglang

Berdasarkan latar belakang di atas maka identifikasi masalah dalam penelitian ini adalah :

1. Belum adanya SPK untuk menentukan lokasi TPA sampah di Kabupaten Pandeglang.

2. Dibutuhkannya SPK untuk membantu Dinas Cipta Karya dalam menentukan lokasi TPA rekomendasi.

Berdasarkan latar belakang yang telah dikemukakan diatas, adapun rumusan masalah pada penelitian ini adalah :

1. Bagaimana membuat aplikasi untuk menentukan lokasi rekomendasi TPA Sampah di Kabupaten Pandeglang menggunakan metode SAW?

2. Bagaimana menerapkan SPK dengan Metode SAW untuk menentukan rekomendasi lokasi TPA Sampah?

Bobot kriteria yang digunakan dalam menentukan lokasi TPA rekomendasi ditentukan oleh pihak Dinas Cipta Karya Tata Ruang dan Kebersihan Kabupaten Pandeglang. Pembuatan aplikasi menggunakan bahasa pemrograman php dan mysql. Lokasi alternatif yang digunakan dalam menentukan TPA Sampah sebanyak 5 lokasi.

\section{METODOLOGI PENELITIAN}

Dalam penelitian ini menggunakan beberapa langkah yaitu

1. Analisa Masalah. Tahap analisa masalah ini merupakan tahap menganalisis permasalahan yang ada untuk dijadikan penelitian.

2. Pengumpulan Data. Teknik pengambilan data berdasarkan dari sumber-sumber data adalah sebagai berikut : a. Wawancara. Penelitian ini mengumpulkan data-data yang dibutuhkan melalui wawancara dengan pegawai dinas Cipta Karya, Tata Ruang dan Kebersihan mengenai lokasi TPA sampah di Kabupaten Pandeglang.

b. Literatur. Literatur atau studi kepustakaan dilakukan dengan mengambil data dari buku, jurnal ataupun artikel mengenai teori dan langkah-langkah dalam pembuatan aplikasi. Sehingga dapat menggunakannya sebagai dasar landasan teori dan perancangan pembuatan aplikasi sistem pendukung keputusan.

3. Analisa Kebutuhan Sistem. Menganalisa data untuk kebutuhan sistem dengan menggunakan analisa yang bersifat membandingkan antara landasan teori yang digunakan dengan obyek.

4. Desain Sistem. Tahapan ini adalah dimana sistem akan dirancang dimulai dari perancangan arsitektur sistem, proses interface, dan interaksi sistem dengan pengguna supaya menghasilkan hasil yang diharapkan.

5. Implementasi. Tahap penerapan sistem agar sistem dapat digunakan dan di operasikan oleh pengguna. Ada beberapa tahapan di dalam penerapan sistem, diantaranya :

a. Kode / Coding. Penulisan kode program atau coding merupakan penerjemahan design dalam bahasa yang bisa dikenali oleh komputer, dan database menggunakan mysql.

b. Testing. Tahap ini merupakan tahap ujicoba, dimana pada tahap ini untuk memastikan program dapat berjalan dengan baik dan efektif. Testing yang dilakukan pada program adalah dengan menggunakan metode blackbox dimana pengujian yang dilakukan hanya mengamati hasil eksekusi program dan memeriksa fungsional dari program.

6. Penyusunan Laporan. Tahap ini dilakukan penyusunan laporan dan menyimpulkan hasil akhir dari tugas akhir tersebut

\subsection{Implementasi Sistem}

\section{HASIL DAN PEMBAHASAN}

Tahap implementasi sistem merupakan tahap penterjemahan perancangan berdasarkan hasil analisis ke dalam suatu bahasa pemrograman tertentuserta penerapan perangkat lunak yang dibangun pada lingkungan yang sesungguhnya.

\subsection{Implementasi Antar Muka}

Halaman Login. Digunakan sebagai keamanan sistem dalam penggunaan aplikasi. Menu login akan tampil ketika aplikasi akan dijalankan, admin diharuskan mengisi user name dan password. Fungsi tombol masuk adalah untuk validasi id pengguna dan password. 


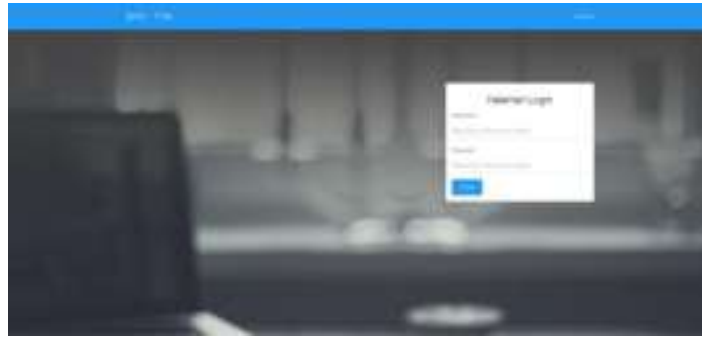

Gambar 1Halaman Login

Halaman home merupakan halaman yang berfungsi untuk mengakses semua halaman yang terdapat dalam aplikasi. Halaman ini akan tampil apabila admin berhasil login, sehingga admin dapat mengakses halaman yang ada sesuai kebutuhan.

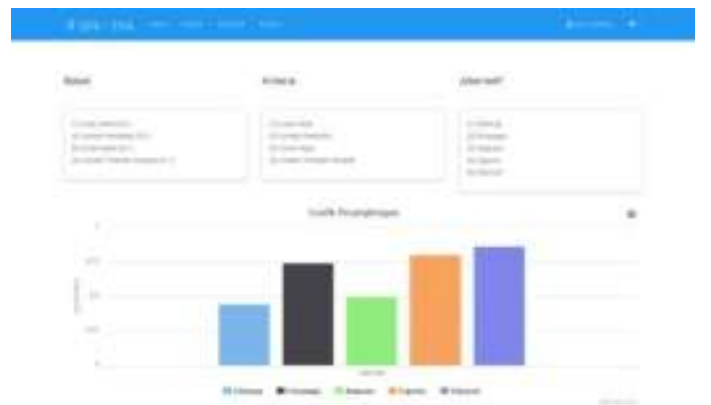

Gambar 2Halaman Home

Halaman profil merupakan halaman yang digunakan oleh pengguna untuk mengelola data pengguna.

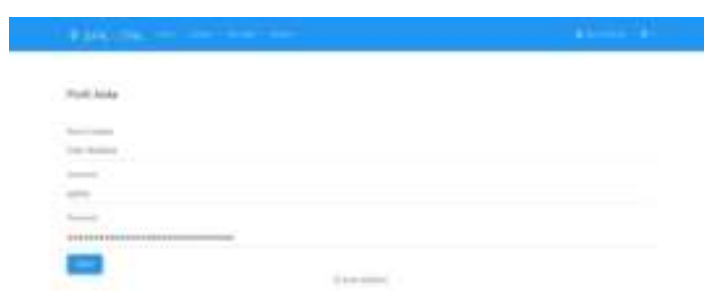

Gambar 3 Halaman Profil

Halaman kelola pengguna merupakan halaman untuk tambah, dan hapus pengguna.

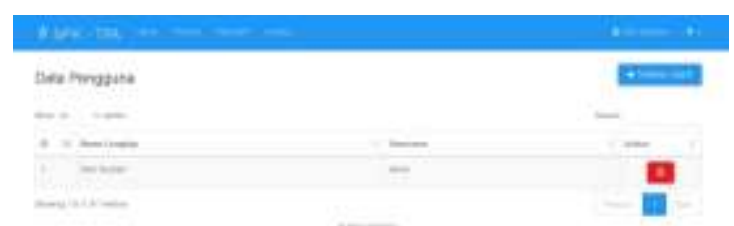

Gambar 4 Halaman Kelola Pengguna
Halaman kriteria merupakan halaman yang digunakan oleh pengguna untuk menambah, mengubah dan menghapus data kriteria.

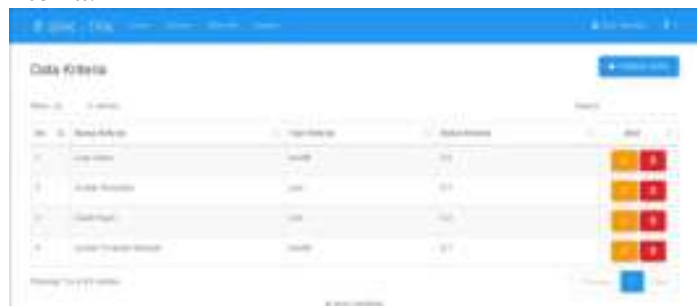

Gambar 5Halaman Kriteria

Halaman alternatif merupakan halaman yang digunakan pengguna untuk menambah, mengubah dan menghapus data alternatif.

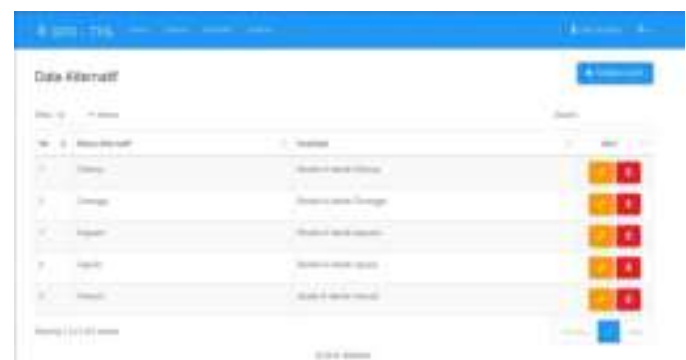

Gambar 6 Halaman Alternatif

Halaman analisa merupakan halaman yang digunakan pengguna untuk menambah, mengubah dan menghapus data alternatif setiap kriteria.

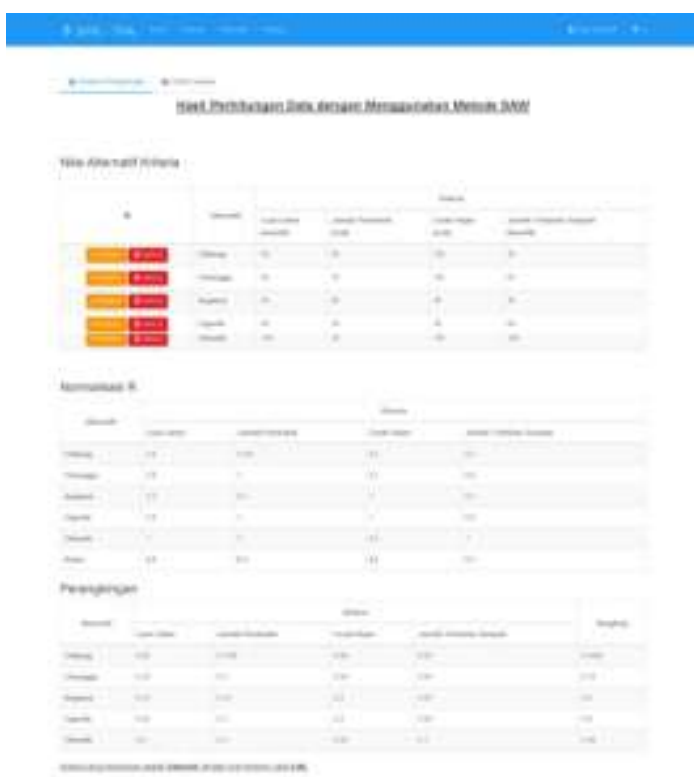

Gambar 7 Halaman Analisa 
Pengujian Sistem

Tabel 1 Deskripsi Hasil Pengujian

\begin{tabular}{|c|c|c|c|c|c|c|c|}
\hline Identifikasi & Deskripsi & Prosedur Pengujian & Masukan & $\begin{array}{l}\text { Keluaran yg } \\
\text { diharapkan }\end{array}$ & $\begin{array}{c}\text { Kriteria Evaluasi } \\
\text { Hasil }\end{array}$ & $\begin{array}{c}\text { Hasil yang } \\
\text { Didapat }\end{array}$ & Kesimpulan \\
\hline SPK-TPA-001 & $\begin{array}{l}\text { Pengujian } \\
\text { Login }\end{array}$ & $\begin{array}{l}\text { Klik aplikasi } \\
\text { Masukan username dan } \\
\text { password, kemudian } \\
\text { tekan tombol login. }\end{array}$ & $\begin{array}{l}\text { Username } \\
\text { Dan passwod }\end{array}$ & $\begin{array}{l}\text { Masuk ke Halaman } \\
\text { utama aplikasi }\end{array}$ & $\begin{array}{l}\text { Berhasil masuk } \\
\text { Kedalam halaman } \\
\text { utama sistem }\end{array}$ & $\begin{array}{l}\text { Berhasil masuk ke } \\
\text { halaman utama sistem }\end{array}$ & Handal \\
\hline SPK-TPA-002 & $\begin{array}{l}\text { Pengujian } \\
\text { Profil }\end{array}$ & $\begin{array}{l}\text { - Klik Profil } \\
\text { - Edit keterangan } \\
\text { Pengguna } \\
\text { - Klik ubah }\end{array}$ & $\begin{array}{l}\text { Nama lengkap, } \\
\text { username, } \\
\text { dan password }\end{array}$ & $\begin{array}{l}\text { Profil pengguna } \\
\text { berubah }\end{array}$ & $\begin{array}{l}\text { Berhasil melakukan } \\
\text { perubahan pada } \\
\text { profil pengguna }\end{array}$ & $\begin{array}{l}\text { Berhasil melakukan } \\
\text { Perubahan pada profil } \\
\text { pengguna }\end{array}$ & Handal \\
\hline SPK-TPA-003 & $\begin{array}{l}\text { Pengujian } \\
\text { Kelola } \\
\text { Pengguna }\end{array}$ & $\begin{array}{l}\text {-Klik kelola pengguna } \\
\text {-Tambah atau hapus } \\
\text { pengguna }\end{array}$ & Pengguna baru & $\begin{array}{l}\text { Data pengguna } \\
\text { Bertambah atau } \\
\text { berkurang }\end{array}$ & $\begin{array}{l}\text { Berhasil menambah } \\
\text { atau mengurangi } \\
\text { data pengguna }\end{array}$ & $\begin{array}{l}\text { Berhasil menambah } \\
\text { Atau mengurangi } \\
\text { data pengguna }\end{array}$ & Handal \\
\hline SPK-TPA-004 & $\begin{array}{l}\text { Pengujian } \\
\text { Kelola } \\
\text { Kriteria }\end{array}$ & $\begin{array}{l}\text {-Klik kriteria } \\
\text {-Tambah, ubah atau } \\
\text { hapus data kriteria yang } \\
\text { diperlukan }\end{array}$ & $\begin{array}{l}\text { Nama, tipe dan } \\
\text { Bobot kriteria }\end{array}$ & $\begin{array}{l}\text { Data kriteria } \\
\text { berubah }\end{array}$ & $\begin{array}{l}\text { Berhasil menambah, } \\
\text { mengubah dan } \\
\text { menghapus data } \\
\text { kriteria }\end{array}$ & $\begin{array}{l}\text { Berhasil menambah, } \\
\text { mengubah dan } \\
\text { menghapus data } \\
\text { kriteria }\end{array}$ & Handal \\
\hline SPK-TPA-005 & $\begin{array}{l}\text { Pengujian } \\
\text { Kelola } \\
\text { Alternatif }\end{array}$ & $\begin{array}{l}\text { - Klik menu alternatif. } \\
\text {-Tambah, ubah atau } \\
\text { hapus data alternatif } \\
\text { yang diperlukan }\end{array}$ & Nilai alternatif & $\begin{array}{l}\text { Data alternatif } \\
\text { Berhasil berubah }\end{array}$ & $\begin{array}{l}\text { Data alternatif } \\
\text { berhasil masuk } \\
\text { database }\end{array}$ & $\begin{array}{l}\text { Data alternatif } \\
\text { berhasil } \\
\text { terupdate }\end{array}$ & Handal \\
\hline SPK-TPA-006 & $\begin{array}{l}\text { Pengujian } \\
\text { Kelola } \\
\text { Alternatif } \\
\text { Kriteria }\end{array}$ & $\begin{array}{l}\text {-Klik alternatif } \\
\text { kriteria } \\
\text {-Tambah, ubah atau } \\
\text { hapus nilai yang } \\
\text { diperlukan }\end{array}$ & $\begin{array}{l}\text { Nilai alternatif } \\
\text { Pada setiap } \\
\text { kriteria }\end{array}$ & $\begin{array}{l}\text { Data nilai alternatif } \\
\text { pada setiap kriteria } \\
\text { berubah }\end{array}$ & $\begin{array}{l}\text { Berhasil menambah, } \\
\text { mengubah dan } \\
\text { menghapus data } \\
\text { nilai alternatif pada } \\
\text { setiap kriteria }\end{array}$ & $\begin{array}{l}\text { Berhasil menambah, } \\
\text { mengubah dan } \\
\text { menghapus data nilai } \\
\text { alternatif pada setiap } \\
\text { kriteria }\end{array}$ & Handal \\
\hline SPK-TPA-007 & $\begin{array}{l}\text { Pengujian } \\
\text { Analisa }\end{array}$ & $\begin{array}{l}\text {-Klik tombol } \\
\text { analisa. } \\
\text {-Lihat atau cetak hasil } \\
\text { analisa perankingan }\end{array}$ & - & $\begin{array}{l}\text { Berhasil } \\
\text { menampilkan dan } \\
\text { mencetak hasil } \\
\text { analisa perankingan }\end{array}$ & $\begin{array}{l}\text { Hasil berhasil } \\
\text { ditampilkan }\end{array}$ & $\begin{array}{l}\text { Hasil analisa } \\
\text { perankingan berhasil } \\
\text { ditampilkan }\end{array}$ & Handal \\
\hline SPK-TPA-008 & $\begin{array}{l}\text { Pengujian } \\
\text { Logout }\end{array}$ & -Klik menu logout & - & $\begin{array}{l}\text { Mengeluarka } n \\
\text { pengguna dari } \\
\text { sistem dan kembali } \\
\text { Kehalaman utama } \\
\text { sistem }\end{array}$ & $\begin{array}{l}\text { Jika berhasil } \\
\text { mengeluarkan } \\
\text { pengguna, maka } \\
\text { sistem akan menuju } \\
\text { kehalaman utama } \\
\text { sistem. }\end{array}$ & $\begin{array}{l}\text { Mengeluarkan } \\
\text { pengguna dari sistem } \\
\text { dan kembali ke } \\
\text { halaman utama sistem }\end{array}$ & Handal \\
\hline
\end{tabular}

\section{Rencana Pengujian Sistem}

Pada pengujian ini, pengujian akan dilakukan secara objektif dimana aplikasi diuji secaralangsung kepada beberapapengguna. Para calon pengguna akan diberikan kuisioner beserta aplikasi, selain itu pengujian dilakukan dengan cara menyebar kuisioner dan aplikasi pada para pengguna. Sampel yang diambil sebanyak 5 orang. Dari hasil kuesionertersebut akan dilakukan perhitungan untuk nantinya dapat diambil kesimpulan penilaian dari para pengguna terhadap aplikasi sistem pendukung keputusan penentuan lokasi TPA sampah di Kabupaten Pandeglang.

Adapun pertanyaan kuesioner yang akan diberikan kepada pengguna adalah sebagai berikut:

A. Bagaimana menurut anda mengenai tingkat kemudahan dalam pengoperasian program aplikasi ?

B. Bagaimana menurut anda mengenai kesesuaian masukan (input) dengan keluaran yang dihasilkan (output)?

C. Bagaimana menurut anda mengenai tampilan program aplikasi ?

Bagaimana menurut anda mengenai kegunaan aplikasi ini dalam membantu anda mengambil keputusan dalam penentuan lokasi TPA sampah?

\section{Hasil Pengujian}

Berdasarkan hasil pengujian yang dilakukan secara objektif kepada pengguna yang telah menggunakan aplikasi sistem pendukung keputusan penentuan lokasi TPA sampah sebanyak 5 responden. Berdasarkan hasil pengujian dengan kasus uji sample di atas dapat ditarik kesimpulan bahwa secara fungsional perangkat lunak sudah sesuai dengan yang di harapkan bahwa tidak ada redudansi pada sistem.Fungsional tambah, ubah dan hapus berfungsi secara baik.Tingkat akurasi perhitungan sudah sesuai $100 \%$ dengan perbandingan perhitungan secara manual

\section{KESIMPULAN}

Setelah melakukan penelitian, perancangan dan implementasi pada aplikasi SPK dapat disimpulkan, yaitu :

- Aplikasi SPK ini dapat digunakan untuk membantu mendukung keputusan dalam memilih lokasi TPA sampah rekomendasi.

- Aplikasi SPK ini mempermudah Dinas Cipta Karya dalam menentukan lokasi TPA sampah di Kabupaten Pandeglang 


\section{REFERENSI}

[1] Arfan, M. (2013). Sistem Pendukumg Keputusan Pemilhan Trainer (Staf Pengajar) Menggunakan Simple Additive Weighting (Studi Kasus : Primagama English Johor). Jurnal Teknik Informatika Vol.5 No.1 2013.

[2] Dharma, A. (2013). "Trik Mudah Menguasai OOP dengan PHP. ”Yogyakarta. Lokomedia.

[3] Dharwiyanti, S. (2003). "Pengantar Unified Modeling Language." Ilmu Komputer.

[4] Hendri, W. (2009). "Pemanfaatan XAMPP Sebagai Web Server, Database, dan FTP Server Di Sekolah.” Pacitan. SMK 1 Pacitan.

[5] Katalog BPS. (2015). Pandeglang Dalam Angka. Pandeglang. Penerbit Badan Pusat Statistik Kabupaten Paandeglang.

[6] Kurniawan, R. (2008). "Membangun situs dengan PHP untuk orang awam." Palembang. Maxikom

[7] Nofriansyah,Dicky. (2014)."Konsep Data Mining Vs Sistem Pendukung Keputusan." Yogyakarta. Penerbit Deepublish.

[8] Sahri, Robi. (2014). Sistem Pendukung Keputusan Pemilihan Pestisida dengan Metode Simple Additive Weighting. Jurnal Teknik Informatika Vol.6 No.1 2014.

[9] Sianipar, R. 2015. PHP \& Mysql - Langkah Demi Langkah. Yogyakarta. Penerbit Andi

[10] Wahyu, Alif dan Noersasongko, Edi. (2014). Sistem Pendukung Keputusan Kelayakan Pemberian Kredit Motor Menggunakan Metode Simple Additive Weighting pada Perusahan Lising HD Finance. Jurnal Sistem Informasi 
